\title{
The properties and performance of polymer fibre reinforced bituminous mixtures
}

\author{
I. Kamaruddin \& M. Napiah \\ Department of Civil Engineering, Universiti Teknologi PETRONAS, \\ Malaysia
}

\begin{abstract}
The low tensile strength of bituminous mixtures has been recognized as a source of its poor performance, particularly that which relates to cracking. Laboratory investigations into improving their tensile properties have been performed utilizing polypropylene and polyester fibres which were added to Hot Rolled Asphalt (HRA) bituminous mixtures as partial replacement of Ordinary Portland Cement (OPC) used as the filler material.

The incorporation of the polymer fibres into the bituminous mixtures altered the rheological properties and behaviour of the resulting binder whilst resulting in a higher optimum bitumen content for the mixture. Laboratory tests showed that the fibres reduced the density, stability and stiffness of the resulting mixture while increasing its porosity and permeability.

Bituminous mixtures containing the fibres displayed lower susceptibility to moisture induced damage. Even though these mixtures have a higher void content than the base mixture, the additional bitumen in the fibre mixtures increased the film thickness on the aggregate particles thus affording greater protection from moisture. The addition of the fibres into the bituminous mixtures caused a slight decrease in the tensile strength and a slight increase in the tensile strain (elongation) at failure, indicating that the additional bitumen added flexibility or extensibility to the mixtures. This was manifested in the higher toughness and energy that was obtained in the mixtures, thus improving its resistance to cracking. This was supported by the fatigue tests which showed improved fatigue performance of the mixtures. The fatigue properties of the fibre mixtures were not enhanced at low strain levels; but at high strain levels, the fibre mixtures provided a far superior performance than the base mixture, making it appealing for use as a base-course in highway construction.
\end{abstract}




\section{Introduction}

Excessive permanent deformation and cracking are generally accepted as the main forms of distress in bituminous road pavements. While permanent deformation occurs predominantly at elevated temperatures, thermal cracking is normally a low temperature phenomenon.

In addition to temperature, cracking can also be brought about by traffic loading. Load associated fatigue cracking is the phenomenon of fracture as a result of repeated or fluctuating stresses brought about by the traffic loads. Traffic loads can cause a pavement structure to flex and the maximum tensile strain will occur at the base of the bituminous layer.

Cracking occurs when the thermally induced tensile stresses together with stresses caused by traffic, exceeds the tensile strength of the material. If the structure is inadequate for the imposed loading conditions, the tensile strength of the material will be exceeded and cracks are likely to initiate, which will be manifested on the surface of the pavement. As a result, it is generally assumed that there is a significant reduction in the load distribution capacity within the pavement.

This paper describes and presents the results of a laboratory investigation to assess the influence of polymer fibres on the properties and performance of Hot Rolled Asphalt (HRA) bituminous mixtures.

\section{Materials used in the investigation}

\subsection{Mineral aggregates, filler and bitumen}

Limestone aggregates and Ordinary Portland Cement (OPC) filler and a binder of nominal penetration 50 were used in this study. Some relevant properties of these materials are shown in Table 1.

Table 1: Properties of the mineral aggregates, filler and bitumen used in the study.

\begin{tabular}{|c|c|c|c|c|}
\hline MATERIAL & $\begin{array}{c}\text { PERCENTAGE } \\
\text { BY WEIGHT (\%) }\end{array}$ & $\begin{array}{c}\text { RELATIVE } \\
\text { DENSITY }\end{array}$ & $\begin{array}{c}\text { ABSORPTION } \\
(\%)\end{array}$ & BS SPECIFICATION \\
\hline $\begin{array}{c}\text { Coarse } \\
\text { Aggregate }\end{array}$ & 35 & 2.75 & 0.47 & \multirow{2}{*}{$\begin{array}{c}\text { BS 594:Part 1:1992 } \\
\text { Table 3, } \\
\text { Type F Wearing Coarse } \\
\text { Designation 30/14 }\end{array}$} \\
\cline { 1 - 4 } $\begin{array}{c}\text { Fine Aggregate } \\
\text { (Sand) }\end{array}$ & 55 & 2.65 & 1.37 & \multirow{2}{*}{ BS 4699:1985 } \\
\hline Filler OPC & 10 & 3.15 & $\begin{array}{c}\text { Softening } \\
\text { Point }\left({ }^{\circ} \mathrm{C}\right)\end{array}$ & $\begin{array}{c}\text { Penetration Index } \\
(\mathrm{PI})\end{array}$ \\
\hline \multirow{2}{*}{ Bitumen } & Penetration $(\mathrm{dmm})$ & 48.5 & -0.37 & \\
\cline { 2 - 4 } & 52 & & & \\
\hline
\end{tabular}

\subsection{Synthetic fibres}

Two types of synthetic polypropylene and polyester fibres were used in this study. The fibres were used as a partial replacement of the filler, on an equal volume basis, at two different concentrations of $0.5 \%$ and $1 \%$ filler/bitumen ratio 
by weight of mix. The fibres; in chopped form; were the by-products of the textile industry and thus their potential use was desirable on environmental grounds.

Some characteristics of the fibres used are shown in Table 2. In order to maintain thermal stability when using the polypropylene fibres, it was decided that the mixing temperature during the preparation of the HRA mixtures should not exceed $140^{\circ} \mathrm{C}$ and compaction be done at $130^{\circ} \mathrm{C}$.

Table 2: Characteristics of fibres used.

\begin{tabular}{|c|c|c|c|c|c|}
\hline FIBRE TYPE & $\begin{array}{c}\text { SPECIFIC } \\
\text { GRAVITY }\end{array}$ & DENIER & $\begin{array}{c}\text { LENGTH } \\
(\mathbf{m m})\end{array}$ & $\begin{array}{c}\text { AVERAGE } \\
\text { DIAMETER } \\
(\boldsymbol{\mu m})\end{array}$ & $\begin{array}{c}\text { DEGRADATION } \\
\text { TEMPERATURE }\end{array}$ \\
\hline $\begin{array}{c}\text { Polypropylene } \\
(\mathrm{PP})\end{array}$ & 0.91 & 6 & 6 & $22^{*}$ & $\approx 160-170$ \\
\hline Polyester(POL) & 1.41 & 3 & 6 & $17^{*}$ & $\approx 250-260$ \\
\hline
\end{tabular}

* Values obtained from 20 readings including a light microscope at 400x magnification.

\section{Engineering properties of bituminous mixtures}

The engineering properties of the bituminous mixtures in this study are summarized in Table 3. Polyester and polypropylene fibres do not prove to be strength enhancing elements when incorporated in bituminous mixes. In fact, the tests conducted have shown that the addition of fibres reduces the strength properties of the bituminous mixes. The results obtained showed that the addition of fibres reduces the density, stability, compacted aggregate density and workability of the mixes. In addition, fibre reinforced bituminous mixes increase the porosity, voids in mineral aggregates, flow, and permeability characteristics of the resulting mixes. The degree of increase is greater with higher fibre concentrations.

Table 3: $\quad$ Properties of bituminous mixtures at optimum bitumen content.

\begin{tabular}{|l|c|c|c|c|c|c|c|}
\hline \multicolumn{1}{|c|}{ Properties } & Control & $\begin{array}{c}\mathbf{0 . 2 5 \%} \\
\mathbf{P P}\end{array}$ & $\begin{array}{c}\mathbf{0 . 5 \%} \\
\mathbf{P P}\end{array}$ & $\begin{array}{c}\mathbf{1 \%} \\
\mathbf{P P}\end{array}$ & $\begin{array}{c}\mathbf{0 . 2 5 \%} \\
\text { POL }\end{array}$ & $\begin{array}{c}\mathbf{0 . 5 \%} \\
\text { POL }\end{array}$ & $\begin{array}{c}\mathbf{1 \%} \\
\text { POL }\end{array}$ \\
\hline $\begin{array}{l}\text { Optimum Bitumen } \\
\text { Content (\%) }\end{array}$ & 7.35 & 7.48 & 7.76 & 8.44 & 7.54 & 7.90 & 8.68 \\
\hline Density (gm/cc) & 2.320 & 2.298 & 2.260 & 2.236 & 2.292 & 2.252 & 2.226 \\
\hline $\begin{array}{l}\text { Compacted Aggregate } \\
\text { Density (gm/cc) }\end{array}$ & 2.15 & 2.13 & 2.09 & 2.05 & 2.12 & 2.08 & 2.04 \\
\hline $\begin{array}{l}\text { Voids in Mineral } \\
\text { Aggregate (\%) }\end{array}$ & 21.4 & 21.6 & 22.4 & 22.6 & 22.0 & 23.3 & 24.3 \\
\hline Porosity (\%) (E-3 cm/s) & 10.0 & 11.5 & 8.0 & 6.0 & 14.0 & 12.0 & 6.0 \\
\hline Permeability (E) & 12.2 & 11.4 & 9.8 & 9.0 & 11.8 & 10.9 & 9.2 \\
\hline Creep Stiffness (MPa) & 8.5 & 8.2 & 7.7 & 7.4 & 7.8 & 7.2 & 7.0 \\
\hline Workability Index & 12.1 & 11.2 & 9.8 & 8.4 & 11.4 & 10.6 & 9.4 \\
\hline Stability (kN) Quotient & 3.90 & 4.17 & 4.62 & 5.7 & 4.2 & 5.0 & 6.18 \\
\hline Flow (mm) & 2.97 & 2.7 & 2.05 & 1.45 & 2.78 & 2.10 & 1.50 \\
\hline $\begin{array}{l}\text { Marshall } \\
\text { kN/mm) }\end{array}$ & & & & & \\
\hline
\end{tabular}

*Note: PP - Polypropylene, POL - Polyester. 
The introduction of fibres into a HRA mix therefore does not act as a reinforcement for the mix nor do they enhance the strength of the mix but act to change the strain allowable in the mix. Incorporation of fibres into a HRA mix would also increase the optimum bitumen content. This increase being higher for increasing fibre concentration. In this study, the polyester fibre incorporated mix displayed higher demand for bitumen than the polypropylene fibre incorporated mix. The additional bitumen is necessary to coat the fibres which is similar to the addition of very fine aggregate. The proper quantity of bitumen for consistent coating of all the particles is different not only for different concentrations but also for different types of fibre which is likely due to the variation in the surface area of the different types of fibres.

\section{Indirect tensile test on bituminous mixtures}

The indirect tensile mode of testing can be used to establish the tensile and structural properties of bituminous mixtures. This test has been used widely by Kennedy and Hudson [6], Kandhal [4] and Wallace and Monismith [10] amongst others. The method has been standardized by both the BSI [2] and the ASTM [1].

The tensile characteristics of bituminous mixtures are evaluated by loading the vertical diameter of a Marshall specimen with a single or repeated compressive load acting parallel to and along the vertical diametrical plane of the specimen. This loading configuration develops a relatively uniform stress perpendicular to the direction of the applied load and along the vertical diametrical plane, ultimately causing the specimen tested to fail by splitting along the vertical diameter.

Table 4: $\quad$ Tensile properties at optimum bitumen content.

\begin{tabular}{|l|c|c|c|c|c|}
\hline & Control & 0.5 PP & 1 PP & 0.5 POL & 1 POL \\
\hline Indirect Tensile Strength (MPa) & 0.925 & 0.87 & 0.83 & 0.78 & 0.73 \\
\hline Strain (mm/mm) & 0.013 & 0.0148 & 0.0168 & 0.0155 & 0.0175 \\
\hline Static Tensile Modulus (MPa) & 152.2 & 136.7 & 116.4 & 106.3 & 96.7 \\
\hline $\begin{array}{l}\text { Indirect Tensile Stiffness Modulus } \\
(\mathrm{MPa})\end{array}$ & 2100 & 2180 & 1970 & 2200 & 1950 \\
\hline Toughness (Joules/cc) & 0.0265 & 0.0295 & 0.0328 & 0.0318 & 0.033 \\
\hline Energy (Joules/cc) & 0.053 & 0.0563 & 0.06 & 0.058 & 0.062 \\
\hline
\end{tabular}

\section{Indirect tensile properties}

From the load deformation characteristics of the indirect tensile test, a number of parameters relating to the properties of the material tested were determined. These include the indirect tensile strength (ITS), strain at failure, tensile modulus of elasticity, toughness and tensile energy. These properties are summarised in Table 4.

In making an overall comparison between the mixes, the control mix can be seen to exhibit greater tensile strength over the fibre-reinforced mixes. The 
addition of fibres caused a reduction in tensile strength in the bituminous mixtures. The mixes were progressively weaker as the percentage of fibres increases.

Mixtures incorporating the polypropylene fibres appear to exhibit higher strength than that of the polyester. The general trend that was observed suggests that the more difficult the fibres were to disperse within the mixtures, the weaker the mixtures were in tensile strength. The fibre-induced weakness in the mixtures may be due to the fibre strands having a tendency to remain together as bundles even with thorough mixing. Consequently, their inclusions in the mix could introduce 'weak spots' that resulted in a lower tensile strength. This behaviour also helps explain the superior performance of the polypropylene mixtures that undergo a more homogeneous mixing as compared to the polyester fibre mixes. In addition, due to the higher viscosity in the polyester-bitumen system, samples of the polyester incorporated mixtures may not have been compacted as well as those of the polypropylene-bitumen system. This resulted in a higher porosity in the polyester mixes which may be responsible for the lower strength obtained.

The tensile strain (elongation) at failure provided a different scenario. The $1 \%$ fibre mixes showed higher strain capacity than those mixes that have $0.5 \%$ fibres as well as the control mix. The highest strains were recorded in the polyester fibre mixture. If the tensile strain at failure can be increased while not appreciably reducing the tensile strength, the mix will be made more flexible. This combination of properties may mean that more energy is required to produce cracking in the material.

Increase in fibre concentration has also resulted in an increase in both the toughness and energy. The fiber incorporated mixtures exhibited greater toughness than the control mix. The polyester fibre mixtures showed greater increase in toughness than that of the polypropylene fibre mix. This behaviour is also true with regards to energy/volume in the mixtures studied.

The higher toughness and energy that characterized the fibre mixes are indicative that these mixes are more resistant to cracking than the control mix. It can be deduced that the addition of fibres in bituminous mixtures reduces the strength properties of the mix but enhances their tensile properties. With this finding in mind, the use of fibre-reinforced mixes is deemed less suitable for use in the wearing course of pavements where the problem of rutting is most expected. They may however be more suited for use as a base-course where the problem of cracking is most likely to occur from the tensile stresses that build up at the base of the bound layer.

\section{Effect of moisture}

The damaging effects of moisture on the physical properties and mechanical behaviour of bituminous mixtures have been the focus of study for many years. Many laboratory tests have been developed in order to evaluate and quantify the amount of damage that is caused by water on bituminous mixtures. The most widely used laboratory method in conducting these tests appear to be the 
immersion-mechanical tests which measures the changes in mechanical properties of the bituminous specimens after exposure to moisture. Typically the results are reported in terms of percentage retained strength of the specimens.

\section{$7 \quad$ Wet-dry indirect tensile test}

The wet-dry indirect tensile test was adopted as a principal measure of the bituminous mixture response to moisture damage. Most evaluations on moisture damage have been assessed quantitatively by mechanical tests in which such properties as loss of tensile strength or decrease of resilient and stiffness moduli have been measured. These are then given in the form of tensile-strength ratio and a moduli ratio, for which the tensile strength modulus of the dry specimens served as references. The tensile strength ratio (TSR) and modulus of elasticity ratio (MER) are dimensionless numbers used to represent the portion of tensile strength and modulus retained following moisture conditioning. Low values indicate high moisture damage. These ratios are given as:

$$
\begin{aligned}
& \text { Tensile Strength Ratio, } T S R=\frac{I T S_{w e t}}{I T S_{d r y}} \\
& \text { Modulus of Elasticity Ratio, } M E R=\frac{M E R_{\text {wet }}}{M E R_{d r y}}
\end{aligned}
$$

Lottman [7] used the static indirect tensile strength test to study the effect of moisture on bituminous mixtures and recommended a minimum tensile strength ratio of 0.7 to differentiate between stripping a non-stripping bituminous mixtures while Maupin [8] reported values of between $0.7-0.75$. Ishai and Nesichi [3] cited values of $60-75 \%$ retained stability values for roads and highway pavements and $75 \%$ for airfield pavements as the quality criteria used in Israel. Kennedy and Anagnos [5] were also of the opinion that mixtures with less than $70 \%$ retained strength are moisture susceptible and would require treatment.

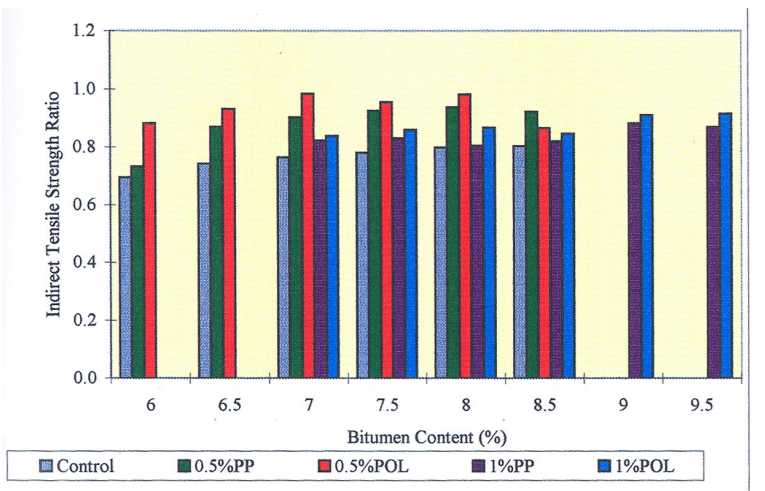

Figure 1: Indirect tensile strength ratios vs. bitumen content. 
Variations of the indirect tensile strength in wet and dry conditions with bitumen content allowed the determination of the indirect tensile strength ratio (TSR). This is shown in Figure 1. It can be seen from the figure that the TSR generally increases with an increase in bitumen content. The control mix showed that they are more vulnerable to moisture damage and reveal a higher level of moisture sensitivity as indicated by the lower tensile strength ratio as compared to the fibre-incorporated mixtures. A lower value of tensile strength ratio is indicative of more damage in the control sample. The control mix had the lowest TSR ranging from $69.5-80.4 \%$. The TSR for the $1 \%$ PP mix ranges from 80.5 $88.2 \%$ while that for the $1 \%$ POL mix ranges from $83.8-91.6 \%$. The highest TSR were obtained in the $0.5 \%$ fibre mixtures. The $0.5 \%$ PP mix had a TSR ranging from $73.2-92.2 \%$ while the TSR for the $0.5 \%$ POL mix ranges from $88.2-98.2 \%$.

Fibres thus showed that they are good tensile reinforcement elements in bituminous mixtures while at the same time indicating that at certain concentrations, they can protect the mixtures from the weakening effect of water. More evidence of the decrease in susceptibility to moisture damage can be seen in the tensile modulus of elasticity ratio (MER) obtained for the various mixtures as shown in Figure 2. It is clear from the figure that the untreated control mixture experiences greater damage as a result of exposure to water. The MER values for the control ranged from $68.4-74.5 \%$ while the fibre modified mixes exhibited higher MER values: 73.6-84.2\% (0.5PP), 80.3-89.3\% (0.5POL), 71.9-76\% (1PP) and $78.1-83.3 \%$ (1POL). As was the case with the TSR, the MER generally also showed higher resistivity of the polyester fibre mixtures over the polypropylene fibre mixtures to moisture damage.

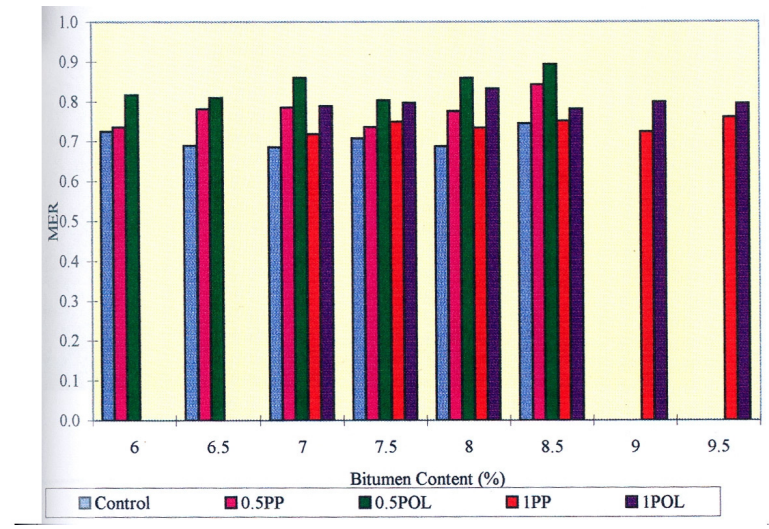

Figure 2: Modulus of elasticity ratio vs. bitumen content.

\section{Fatigue relationship}

Fatigue tests can be carried out in two principal methods, namely the constant stress tests where the stress level is kept constant throughout the test and the constant strain tests where the magnitude of the peak cyclic strain is kept 
constant throughout the test. Before the fatigue performance of a bituminous material can be assessed, the failure of the specimen tested must be consistently defined.

Defining the failure criterion in the constant stress mode is relatively easy as the specimens undergo a relatively short crack propagation period. Hence, the failure point is taken as when the specimen has completely failed. However, in the constant strain mode of loading, the failure point is not very well defined, due to the large amount of crack propagation included in the test. An arbitrary point of failure must thus be assumed which is normally defined as the point when the specimen has reached a reduction in its initial stiffness of $50 \%$ or in a practical term is the point when the stress applied has been halved to achieve a constant strain.

A linear relationship exists between the $\log$ of stress $\sigma$, or strain $\varepsilon$, and the $\log$ of the number of load repetitions, $N_{f}$ to failure. The failure criteria can therefore be expressed as Log. stress against log. load applications and log. strain against log. load applications. This can be written in the form:

$$
\log (\sigma \text { or } \varepsilon)=\mathrm{a}+\mathrm{b} \log N_{f}
$$

For the strain controlled tests, the results are normally presented in the form:

$$
N_{f}=A\left(\frac{1}{\varepsilon}\right)^{b}
$$

while in the stress controlled tests, the results are presented in the form

$$
N_{f}=C\left(\frac{1}{\sigma}\right)^{d}
$$

where $N_{f}=$ Number of load applications to failure

$\sigma, \varepsilon=$ Tensile strain or stress repeatedly applied load

$A, b, C, d=$ Materials coefficients

\section{Flexural beam fatigue test}

The flexural beam fatigue test was used to study the fatigue behaviour of the mixtures. This involved a bituminous beam subjected to cyclic loading and resting on a rubber support which simulates the elastic foundation in a road structure. A crack was induced in the beam and the time and number of cycles taken for the cracks to propagate in the control and fibre-reinforced beams were compared. The test used is essentially a simple arrangement and does not simulate the more complicated stress regime at the crack tip that occurs during a load pulse caused by traffic loading. Despite this limitation, the test produces useful data in showing the benefit, or otherwise, of reinforcing bituminous mixtures with the synthetic fibres.

The bituminous mixtures for the fabrication of the beams were prepared in the laboratory. The amount of materials required to produce a $500 \times 100 \times 100 \mathrm{~mm}$ 
beam that have density close to that of the mix compacted with the Gyratory Testing Machine (GTM) were calculated and prepared.

\section{Flexural beam fatigue test results}

The beam flexural fatigue test was conducted at ambient temperature and at three different stress levels to determine the relationships between initial strain and the number of load applications of failure. The results of the fatigue tests are summarized in Table 5. Figure 3 is a comparison of the fatigue behavior of the mixes at their optimum bitumen content. The results indicated that the beams that were reinforced with fibres showed superior fatigue properties when compared to the control beams. The effect of higher bitumen content in the fibre mixes must have contributed to the superior fatigue behaviour. Mixes with $1 \%$ fibre concentration displayed better fatigue behaviour than mixes with $0.5 \%$ fibre concentration. The polyester mixes exhibited better fatigue performance than the polypropylene mixes. This is in agreement with the findings where the polyester showed higher toughness and energy per unit volume than those of the polypropylene mixes in the indirect tensile tests.

Table 5: $\quad$ Summary of fatigue test results.

\begin{tabular}{|c|c|c|c|c|c|}
\hline $\begin{array}{l}\text { Test Series and Binder } \\
\text { Content (\%) }\end{array}$ & $\begin{array}{l}\text { Stress } \\
\text { (MPa) }\end{array}$ & $\begin{array}{l}\text { Initial } \\
\text { Strain } \\
\left(\times 10^{-6}\right)\end{array}$ & $\begin{array}{l}\text { Stiffness } \\
\text { (GPa) }\end{array}$ & $\begin{array}{l}\text { Porosity } \\
(\%)\end{array}$ & $\begin{array}{l}\text { Fatigue Life } \\
\qquad\left(\mathbf{N}_{\mathrm{f}}\right)\end{array}$ \\
\hline \multirow{3}{*}{$\begin{array}{l}\text { Control (OBC) } \\
7.35 \% \text { BC }\end{array}$} & 0.683 & 172 & 3.971 & 4.92 & 169000 \\
\hline & 1.076 & 233 & 4.618 & 4.88 & 46520 \\
\hline & 1.267 & 306 & 4.141 & 4.68 & 13600 \\
\hline \multirow{3}{*}{$\begin{array}{l}0.5 \mathrm{PP}(\mathrm{OBC}) \\
7.76 \% \mathrm{BC}\end{array}$} & 0.341 & 165 & 2.067 & 5.49 & 244610 \\
\hline & 0.724 & 351 & 2.063 & 5.57 & 18970 \\
\hline & 1.076 & 882 & 2.131 & 5.74 & 795 \\
\hline \multirow{3}{*}{$\begin{array}{l}0.5 \mathrm{POL}(\mathrm{OBC}) \\
7.9 \% \mathrm{BC}\end{array}$} & 0.532 & 202 & 2.634 & 5.29 & 201780 \\
\hline & 0.679 & 381 & 1.782 & 5.33 & 25330 \\
\hline & 1.021 & 475 & 2.149 & 5.04 & 15160 \\
\hline \multirow{3}{*}{$\begin{array}{l}1 \mathrm{PP}(\mathrm{OBC}) \\
8.4 \% \mathrm{BC}\end{array}$} & 0.330 & 215 & 1.535 & 4.29 & 170000 \\
\hline & 1.297 & 750 & 1.729 & 4.08 & 8000 \\
\hline & 1.825 & 1400 & 1.304 & 3.38 & 800 \\
\hline \multirow{3}{*}{$\begin{array}{l}1 \mathrm{POL}(\mathrm{OBC}) \\
8.68 \% \mathrm{BC}\end{array}$} & 0.33 & 192 & 1.719 & 4.16 & 576240 \\
\hline & 0.968 & 582 & 1.663 & 3.95 & 17340 \\
\hline & 1.514 & 1072 & 1.412 & 4.08 & 3710 \\
\hline
\end{tabular}

Figure 3 also indicated that at a high strain levels or low number of cycles to failure $\mathrm{N}$, the fibre mixes exhibit superior performance. The fatigue lines for the fibre mixes are always higher than the control but these lines converge at high number of cycles to failure $\mathrm{N}$ and low strain. This means that the fibre reinforced HRA mixes will provide about the same fatigue performance as the control mixes at low strain levels, but at high strain levels, the fibre reinforced mixtures will provide superior fatigue performance. This may have a practical application in that for major highways with stiff bases and subgrades, reinforcement of bituminous mixes with fibres may not provide enhanced benefits of fatigue performance as compared to conventional HRA mixes. However, for secondary 
roads with weak bases and subgrades and thin pavement surfacings, the use of fibre-reinforced bituminous mixes as the surface course may be a viable alternative for increasing the pavement service life.

All the fatigue beams were prepared using the same compactive effort. It should be pointed out that the air void contents (porosity) of the fibre-reinforced specimens were greater than those of the control specimens. The significance of this lies in the fact that the fatigue performance of bituminous mixes will usually suffer when the air voids contents is increased. It appears that fibres have the potential to increase fatigue performance of HRA mixes provided adequate compaction is achieved.

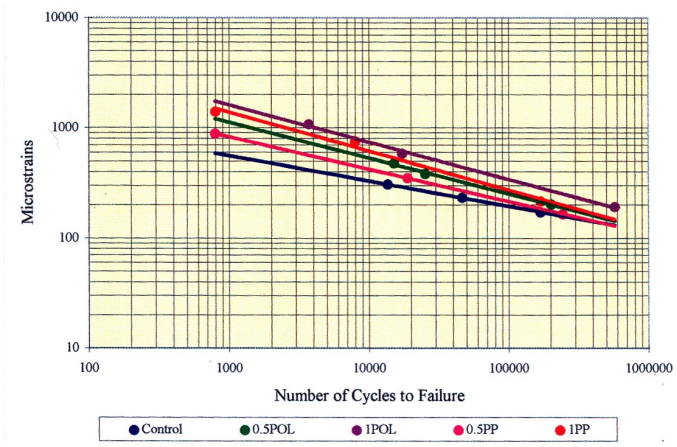

Figure 3: Fatigue lines for control and fibre reinforced mixes at optimum bitumen content.

\section{Conclusion}

Based on the work done, the following conclusions can be drawn:

1 Addition of synthetic fibres to the HRA bituminous mix decreases the density and increases the resulting air void content when the compactive effort remains the same. As the quantity of the fibre increases, the amount of air voids also increases. This is important from the stand point of achieving a desired density since mixtures with fibres would require greater compactive effort to achieve similar porosity than the conventional HRA mixtures

2 Based on a limited number of constant stress flexural fatigue test, it appears that the incorporation of synthetic fibres in Hot-Rolled Asphalt (HRA) mixtures have the potential of improving the fatigue performance of the mix.

3 Fatigue testing confirm the high strain capacity of the fibre-modified mixes owing to their higher bitumen content and the thicker bitumen film coating the aggregates.

4 The air void content of the fiber-modified specimens was higher than that of the control. This is significant in that the fatigue performance would usually suffer when the void content is increased. The test results indicate that the fibre 
mixtures provide about the same fatigue performance as the control at low strain levels. At high strain levels however, the fibre-modified mixes provided superior fatigue performance, making it appealing for use as a base-course material in highway construction.

\section{References}

[1] America Society for Testing of Materials, ASTM D 4123 - 82 (Reapproved 1987), Standard Test Method for Indirect Tension Test for Resilient Modulus of Bituminous Mixtures, ASTM, 1982

[2] British Standard Institution, Draft for Standard Development for Determination of the Indirect Tensile Stiffness Modulus if Bituminous Mixture DD213, 1993

[3] Ishai, I. and Nesichi, S., "Laboratory Evaluation of Moisture Damage to Bituminous Paving Mixtures by Long-term Hot Immersion", Transportation Research Record No. 1171, 1988, pp. 12-17

[4] Kandhal, P.J., "Evaluation of Six AC-20 Asphalt Cement by Use of the Indirect Tensile Test", Transportation Research Record 712, 1979

[5] Kennedy, T.W. and Anagnos, J.N., "Wet-Dry Indirect Tensile Test for Evaluating Moisture Susceptibility of Asphalt Mixtures", Centre for Transportation Research, University of Texas at Austin, Research Report 253-8, Nov. 1984

[6] Kennedy, T.W. and Hudson, W.R., "Application of the Indirect Tensile Test to Stabilised Materials", Highway Research Record No. 235, Highway Research Board, 1968, pp. 36-48

[7] Lottman, R.P., "Laboratory Test Method for Predicting Moisture-Induced Damage to Asphalt Concrete". Transportation Research Record 843, Transportation Research Board, National Research Council, Washington D.C., 1982

[8] Maupin Jr. G.W., "The Use of Anti-stripping Additives in Virginia", Proceedings of the Association of Asphalt Paving Technologists, Vol. 51, 1982

[9] Read, J.M. and Collop, A.C., "Practical Fatigue Characterization of Bituminous Paving Mixture", Proceedings of the Association of Asphalt Paving Technologists, Vol. 66, 1997, pp. 74-108

[10] Wallace, K. and Monismith, C.L., "Diametrical Modulus Testing on NonLinear Pavement Materials", Proceedings of the Association of Asphalt paving Technologists, Vol. 49, 1980, pp. 633-652 